\title{
Chapter 3 \\ Mediation and Conciliation in Collective \\ Labor Conflicts in Belgium
}

\author{
Tijs Besieux, Elisabet Lenaerts, Olivier Van Loo and Valerie Veldeman
}

\section{The Case}

A large foreign owned company has multiple production facilities in Belgium, one of its prime production locations. In the years leading up to the conflict, the company suffers from a drop in demand for production in Europe because of the financial crisis and its own activities in other regions of the world. Restructuring is announced and production is dialed back in Belgium which results in over 200 people becoming temporarily unemployed. There are smallscale employee actions and protests regarding the current situation leading to discussions at the organizational level.

A couple of years later, further cost cutting is announced and one of the facilities stops production for an entire month resulting in economical unemployment of over 400 employees. The company reports a heavy loss and has to fire dozens of employees while announcing further restructuring. Coinciding with the ongoing restructuring, the CEO announces his departure from the company.

During the reorganizations, biennial negotiations commence regarding the Collective Labor Agreement. Unions wanted to connect a strong social plan to regular negotiations, however, these negotiations failed rather quickly as two of the three major unions refuse to sign the proposed Collective Labor Agreement.

T. Besieux ( $₫) \cdot$ E. Lenaerts $\cdot$ O. Van Loo $\cdot$ V. Veldeman

Leuven, Belgium

e-mail: tijs.besieux@kuleuven.be 
Following the failed negotiations, these unions block the gates of the company and start a general strike. The company accuses the unions of playing power games, using failed negotiations as an excuse while the unions stated that the employer pushes decisions without any decision power or respect for employees.

The company sends a judicial officer to the site to force access to the site and identify several of the people responsible for the strike while threatening with judicial consequences. The company one-sidedly cancels some of the previous collective labor agreements, resulting in general anger among the unions. The company sues several employees but the court does not agree with them. Simultaneously, the company announces further firings unrelated to the current conflict.

After a six-week strike, a first conciliation meeting fails and does not produce any form of agreement.

External pressure is increased as the board implies that closing the facility altogether is an option should problems persist. Employees reach out to government officials in hopes of intervening.

Local management and the employers' federation initiate a second conciliation attempt.

After almost two months of striking, both parties reach an agreement ratified by two thirds of unionized employees in a vote.

The parties agreed to a new Collective Labor Agreement as well as formal arrangements regarding further collaboration. The mediator also advised the company not to pursue further sanctions.

Despite of the agreements and advice, a climate of unrest remains while the parent company announces further restructuring and global cost cutting. A smaller strike occurred the next year after management gave a single employee a written warning. Employees perceived the warning as revenge from management and indicates the conflict's influence more than a year later.

\subsection{Introduction}

The Belgian Federal Public Service Employment, Labor and Social Dialogue offers conciliation and mediation services to the private and the public sector in collective labor disputes (FOD WASO, 2017). This government agency acts as a third party to mediate collective conflicts at the level of the organization in the private sector, primarily through the Conciliation Board (further referred to as $\mathrm{CB}$ ), created within a Joint Committee. A Joint Committee is the bi-partite collective bargaining body at sector level, composed by a representation of the social partners and chaired by a Federal Labor Mediator (European Foundation for the Improvement of Living and 
Working Conditions, 2006). Collective dispute mediation in the private sector has a long-standing tradition in Belgium. In 1968, a legal framework anchored the system of collective dispute mediation, mandating federal mediators to resolve disputes between employers and employees in the CB (Wet van 5 December 1968).

In the public sector however, mediation is not yet widespread because the government implemented it only rather recently (since 2013). In the public sector, the mediator solely manages the process between the conflicting parties, without the advantage of a Conciliation Board.

In the current research, the terms 'mediation' and 'conciliation' were often found in documents and during interviews as referring to the same underlying meaning. Even the name of the governmental agency in Dutch refers to mediation ('bemiddeling'), whilst in French it refers to conciliation ('conciliation') (FOD WASO, 2017). In the Belgian context, one could distinguish conciliation from mediation based on the stage of the process. That is, conciliation is more referred to in the context of the conciliation board, while mediation is more referred to as a potential next step when the conciliation board does not come to an agreement. However, the techniques and skills underlying conciliation and mediation are referred to by the interviewees in this study as the same.

According to the 'Institut der deutschen Wirtschaft' estimates, in 2016 a total of 79 labor days per 1.000 employees were 'lost' due to strikes. Belgium ranks fourth compared to 21 other OECD countries. Only France (123), Denmark (118) and Canada (87) score higher (Institut der deutscheun Wirtschaft, 2017). Approximately 3.5 million Belgians are member of one of the three major unions, $65 \%$ of them are currently employed. This represents a union density of $51.2 \%$. Including smaller, independent unions, the total union density for Belgium is $55.1 \%$.

\section{Private Sector}

Belgium's private sector has a tradition of social dialogue involving unions, employers and government (Devos, Mus, \& Humblet, 2011). This dialogue expresses itself in several forms, and at different levels. It can be found in (but not limited to) the institution of joint committees, the conciliation board and government policymaking. Joint committees for instance, are institutions where an equal number of the sector's employer and employee organizations negotiate collective labor agreements and are responsible for their supervision (Devos, 2009). Joint committees also advise the National Labor Council and government. These instances of social dialogue occur at the sector, federal, regional as well as organizational level (Humblet \& Cox, 2011). In the private sector, there are currently 13 mediators ( 8 women; 5 men).

The institutional system of social dialogue and negotiation between social partners knows a longstanding history dating back to 1945 . This makes the system a fundament in the current corporate and political system. Belgium as a country has a rather strong history and presence of labor unions and unionization with major unions tied to affiliate political parties (Van Gyes, Segers, \& Henderickx, 2009). The individuals involved have developed personal relationships and mutual understandings, resulting in a strong informal social network underlying the system's working. Organization 
and facilitation of this social dialogue falls under the jurisdiction of the Belgian Federal Public Service Employment, Labor and Social Dialogue. This Government Service reports to the Belgian minister of labor and has its administrative chair in Brussels.

\section{Public Sector}

Third party intervention is a recent phenomenon in the public sector and, in contrast to the private sector, has not yet known any significant growth. Policy makers decided to implement a system of social dialogue and opportunities for mediation as an alternative to implementing a system of obligated provision of services during a strike. This makes the origin of mediation and third party intervention by government mediators a politically motivated solution, and thus not necessarily based on demands or needs of the involved parties. The agency hired three mediators specifically for the public sector in 2013, with one of them leaving some time afterwards. The goal of the mediators is to set up a system in analogy to the private sector. Because the mediator does not chair a joint committee in the public sector, utilization of social networks and contacts was relatively limited.

During the set-up of the system, the primary focus was building these social contacts/networks, resulting in a promotional tour of government agencies. Simultaneous to this effort, a conflict arose in one of Belgium's governmental departments. One of the mediators used this conflict as an opportunity to design and test strategies and methods. Strong regional differences appear between Flanders and Wallonia. There was a notably stronger willingness in Flanders than Wallonia to participate in this form of mediation/dialogue, because of earlier positive experiences with mediation in the Flemish region. Within the Flemish government, a well-regarded government official was already experimenting with mediation before official implementation, causing some familiarity with, and a positive attitude towards, the concept.

\subsection{Characteristics of the System}

\section{Private Sector}

The Belgian Federal Public Service Employment, Labor and Social Dialogue almost exclusively organizes collective dispute mediation and conciliation during conflicts. This is a result of the long history of social dialogue in Belgium, further anchored through the law of 1968. Although third parties outside of the government might operate during these conflicts, none of the interviewees mentioned this (Fig. 3.1).

When a conflict arises in an organization between-for instance-local management and the trade union delegation, further steps in the conflict differ. Whilst HR or management enter discussions directly, a local representative (secretary) of the involved union mostly assists employees.

If these negotiations fail, the employer or union representative have the option to contact their corresponding representative organization (employer's federation or 


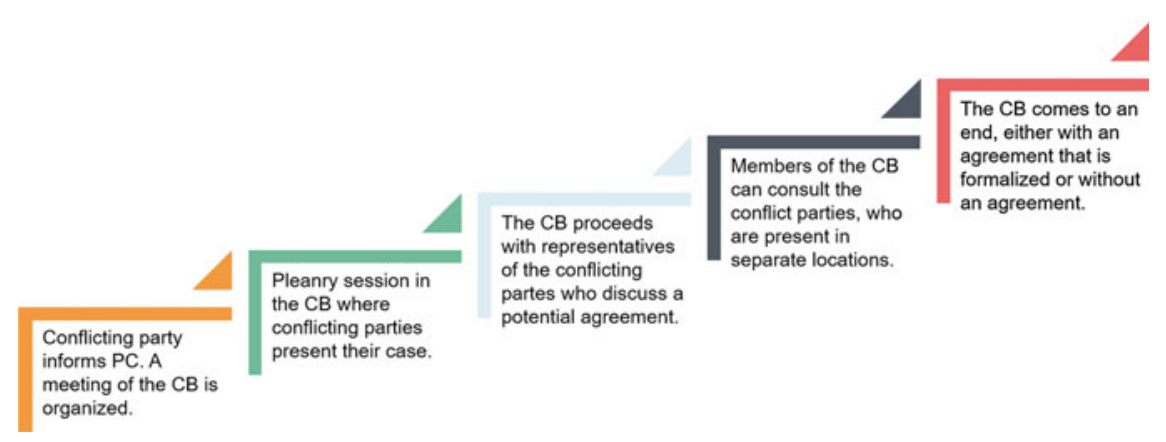

Fig. 3.1 Five-step process of the Conciliation Board (Belgium)

union relevant to sector) and request the formation of a 'Conciliation Board' (CB). In reality, unions primarily request CB's, as they are most often the complainant in these conflicts.

When the representative organization receives the request, they usually make an inquiry about the specifics and context of the conflict to assess whether it is suited for a CB. These organizations will ideally look at previous efforts towards conciliation, subject (collective vs. individual), as well as severity of the current conflict. It thus acts as a second filter, with the first being the management or union representative, in assessing the severity of a conflict and the involvement of 3rd parties.

If the representative organization judges the conflict to be severe enough or a candidate for conciliation, he/she contacts the chair of the sector's joint committee and requests the formation of a $\mathrm{CB}$. The chair will act as both mediator and chair of this $\mathrm{CB}$, assisted by a secretary of the government. Other members of the $\mathrm{CB}$ are representatives of unions and the employer organizations. If the conflict is very complex, the mediator can ask for assistance from a colleague from the Belgian Federal Public Service Employment, Labor and Social Dialogue.

After the formation of the committee, the appointed members will enter negotiations concerning the conflict and possible solutions. The conflicting parties will be present at the location but separated from the actual negotiation and each other. Their role is to inform the committee of their viewpoints and problems at the beginning of the session and to be consulted about their willingness to accept proposed solutions.

The conflict is, in a sense, transferred to the committee's members who negotiate on their behalf. The chair/mediator is responsible for the negotiations between the committee's members, and mediates between the present. The committee does not have any strict legal authority to enforce agreements, but does have the necessary moral authority because of the involvement of both government and representative organizations. The conflicting parties therefore generally follow reached agreements - although no exact data are kept. The committee can also give further recommendations concerning dialogue at the organizational level, although enacting and reporting these recommendations is the responsibility of the conflicting parties. 
After concluding the $\mathrm{BC}$, the parties generally implement a cooling-off period which dictates a certain timeframe during which no actions/strikes can be taken.

The Collective Labor Agreement stipulates specific guidelines about timing, formation and minimum requirements (number of required representatives for example) of the committee and can thus vary according to sector or level. The CB is however, a necessary procedure if employees wish to take action in the form of for example a strike. Should a CB fail in its attempt to resolve the conflict, the employees are justified in taking action and striking, but no sooner. Spontaneous actions or strikes because of organizational conflict do still occur. When this happens, a CB forms as soon as possible and will skip some of the aforementioned procedural steps.

\section{Public Sector}

Because the public sector lacks the history and institutions such as the joint committee, its procedures are not as clear as in the private sector. As mentioned earlier, no strong social network underlies its working and limits the visibility of current conflicts as well as actual conciliation requests. In this case, one of the conflicting parties' representative organizations still requests conciliation, but no formal committee is appointed. However, representatives can still be involved in the mediation and the involved number of people splits up and separates should the group be too large. In comparison to the private sector, the procedure does not stipulate strict regulations regarding the timing of strikes or conciliation as a necessary step.

\section{Evaluation of stakeholders on the system}

\section{Mediators/facilitators}

\section{Private Sector}

Mediators are satisfied with promotion of and general familiarity with the system in the private sector. They see general promotion of the system's use as a responsibility of the social partners (employer/employee organizations) as they play a crucial part in informing, and guiding their members. The mediators are also generally very positive about the intervention system, and particularly its financial and relational benefits compared to litigation or other judicial processes. According to the mediators, the familiarity with the system gives it a big advantage, as well as the built-up respect and trust in the process due to its long history. Familiarity with the intervention mechanism is also noted as one of the reasons why the different parties generally respect agreements.

An issue however is that there seems to be little structural follow-up of conflicts after the $\mathrm{CB}$ has intervened. Mediators however do report that feedback occurs more spontaneously, as they meet the involved parties at other occasions.

Another potential issue is that parties request a $\mathrm{CB}$ too late. Every party of the joint committee can request a $\mathrm{CB}$; however, the employee organizations request most of them. The employer also has more decision power and therefore does not feel the same need to use the system, using it only in the most urgent cases. 
The mediators themselves do not describe their different structural roles (chair of joint committee, $\mathrm{CB}$ and mediator) as a hindrance. Their position allows them to build trust with the social partners more easily through increased contact with relevant individuals. These contacts also allow them to stay up-to-date with the state of affairs in the sector.

\section{Public Sector}

At the time of the interviews (2017-2018), the public sector had not implemented the role of the mediator him/herself effectively. The very limited demand for interventions in the public sector, and lack of other responsibilities such as the joint committee, made the workload very unpredictable. Long periods of little work contrasted intense periods with a disproportionately high workload causing problems with planning and work-life balance. Although mediators are, in general, very positive about the mediation process, they indicated higher-level issues regarding the prevalence and demand of interventions. Interviewees described two main factors for these problems. A first explanation was the limited experience parties had with the system. Due to the system's origin in the public sector as a political solution, it did not develop from actual demands and needs of the parties involved in these conflicts. The lack of extensive social network as seen in the private sector hinders the mediator's functioning by limiting access to information regarding current affairs and conflicts. Interviewees said, however, that the success of several cases increased the interest and information requests from involved parties significantly. This might be a sign that through word-of-mouth advertising and experience, the system's usage and popularity can grow over time.

A second explanation for limited demand lies in the reluctance of employees to request interventions due to fear of reprisal. Interviewees note a power imbalance in favor of the involved government agency and fear of their reaction (budget cuts, staffing decrease, demotion, etc.) has fostered a culture where parties keep conflicts in-house. Varying accordingly with the significance of a conflict, the government's role can be problematic as they are both party and have absolute power when it comes to the final decision and its validation. This can lead to a loss of engagement and involvement from the other party in the negotiation. Interviewees described how mediators received many informal requests for information about the system/procedure, but this seldom led to an actual intervention request.

\section{Conciliation board members}

Most of the CB members perceive the conciliation system as very valuable. They see the procedure as an important tool in preventing further escalations as well alleviating some of the conflict intensity. The procedure can be used to sometimes force a discussion between parties where there was no willingness to negotiate beforehand.

In general, there is a strong emphasis on local dialogue and prevention of CBs where possible. The outcome of the $\mathrm{CB}$ is always uncertain to the conflicting parties and can legitimize further employee actions if no agreement is reached. CBs can be perceived as a failure of the own dialogue and is thus not always a clear option 
for companies leading to many trying to keep the conflict in-house. Although not as expensive as litigation, CBs are still expensive, as they require a substantive number of people including management to spend an entire day at the CB.

Interviewees describe that they use the $\mathrm{CB}$ primarily to revitalize dialogue and negotiations at the organizational level by providing indications, recommendations and highlighting common ground between the parties.

A number of $\mathrm{CB}$ members indicate that conflicting parties request the $\mathrm{CB}$ too early, thus before depleting all opportunities for local dialogue. This is problematic, as the $\mathrm{CB}$ is a final step should local negotiations fail, otherwise there is a risk of undermining the CB's authority and relevance. Timing is also used as an important tool during the procedure. Sometimes, members postpone the CB date if they believe the conflict will solve itself at the local level. The cooling-off period after every CB is also very valuable when continuing local negotiations, as possible talking points have already been discussed during the CB.

Committee members relate the general decline in CB's to a current trend of further regulation. As an example, salary increases depended on indicative norms in the past while nowadays there are strict norms in place. Besides the declining number of $\mathrm{CBs}$, respect for the procedure has fallen as well. To exemplify, no strike should occur before the $\mathrm{CB}$ has convened. Interviewees indicate that parties respect this agreement less and less. Employees and unions increasingly do not follow the steps outlined by previous agreements leading to frustrations of the employer and employers' federation. Similar to earlier findings, members raise questions regarding investment of resources as $\mathrm{CB}$ members perceived the mediators to be understaffed.

\section{Conflicting parties}

All interviewed parties were positive about the existence of the $\mathrm{CB}$ and saw its value although they also raised some concerns regarding recent developments. Because of an increased presence of multinational companies, there is an evolution in the mandate of the company representatives at the conciliation board. In the past, involved unions/employees were able to negotiate directly with the people in charge. Nowadays, the present party often has to contact a board of directors or management abroad to get the necessary mandate should new topics arise. This also incorporates the danger of importing different corporate cultures where involved parties do not see social dialogue as essential. Larger companies within a sector also have the added complication that agreements made with them, can be seen as precedents for further negotiations in the smaller companies.

Users of the system agree that the CB should be a last step when confronted with a conflict and that its primary purpose is to revitalize the organizational dialogue.

Additionally, interviewees describe the importance for employers to perceive the system that can help prevent employee actions, as this is not always the case.

A final remark can be made regarding the mandatory nature of the $\mathrm{CB}$, which is generally seen as a positive element but can make CBs useless and seem like a necessary hurdle when for instance parties are set on action or already know that no agreement can be reached. 


\subsection{Characteristics of the Mediators or Facilitators and the Third Party Procedures}

The mediators had an average age of 48 years and out of the 16 mediators employed by the Belgian Federal Public Service Employment, Labor and Social Dialogue, nine were female. The mediators had an average experience of 9 years in their role as a government-employed mediator. Previous experience as mediators varied strongly ranging from an extensive background in mediation to the minimum requirements of the role (stipulated further in the text).

Only two of these mediators are currently active in the public sector. Most mediators have a law degree with a minority coming from different educational backgrounds. In the past, the government provided additional training in negotiation and mediation but current budget restraints have led to the cancellation of these trainings. Thus, further education and training is, in effect, the responsibility of the individual mediator and relies on his/her own initiative. As a result, only half of the interviewed mediators reported to having followed at least one additional training in line with their current function.

The mediators do not actively save data related to their interventions; therefore, it is not easy to identify the precise number of interventions. The reluctance to save data stems from the confidential nature of these interventions, the opinion that the mediators' work is not easily quantifiable and the possible misrepresentation of these numbers (e.g. ending the intervention in a non-agreement does not mean the process failed). Interviewees indicated having vast experience, both with reconciliation and mediation.

\section{Selection, recruitment and evaluation}

Recently, the recruitment procedure was reformed. It used to rely exclusively on political appointments without a formal selection process. Social partners were informally consulted during this process.

As of 2009, selection and recruitment takes place through the government recruitment office. To be considered for the position, candidates need to meet the following requirements ${ }^{1}$ :

Education and professional experience:

- A master's degree (or similar degree of at least 4 years) and at least 6 years' experience in social matters of which at least 4 years in collective bargaining;

- Or a bachelor's degree (or similar degree of at least 2 years) and at least 10 years' experience in social matters of which at least 6 years in collective bargaining.

The selection procedure consists of an assessment center to test for cognitive abilities, knowledge of collective labor law, and a case presentation for a panel of experts.

\footnotetext{
${ }^{1}$ Stipulated by a new Royal Decree signed 27/10/2009; promulgated 19/11/2009.
} 
Once recruited, an experienced mediator mentors the new mediator during their first year. The new mediator makes progress reports of experience gained and educational programs completed at regular intervals.

Mediators will also need to deliver a paper at the end of the first year analyzing a topic of interest to the team. The mentor and the director-general provides a final evaluation of the paper and a global report of the first year. This procedure is a condition for becoming a statutory civil servant.

There is no institutionalized evaluation of mediators or the system as a whole, based on a case-by-case basis. Interviewees provide different reasons for the lack of a structural evaluation. A first reason is the reporting line regarding social conflicts. The mediators report to the designated Minister of labor, thus the director-general did not design an evaluation system because he/she did not have the authority to evaluate the work of the mediators. A second reason is the demanding job requirements. Mediators reported having a very busy schedule and thus did not prioritize on evaluation the system. A final reason is involved parties might use the evaluation of the system/mediator during conflicts when it suits them best.

\section{Mediation approach}

Based on the interviews, we did not identify a shared mediation style within the well-structured procedures that exist for the CB. Two main reasons account for this finding: (1) no joint training, and (2) lack of structural dialogue and reflection among mediators to assess their mediation style. Their previous work experiences before joining Belgian Federal Public Service Employment, Labor and Social Dialogue result in a pre-existing individual style.

The individual mediators emphasize different aspects or vary in approach but do operate within the same broader structure aligning all mediators along the same procedure and general approach. Because the $\mathrm{CB}$ is a de facto partner of the mediator in the conciliation process, the styles and approaches of these players also influence the ultimate approach largely. The majority of mediators did agree that the mediator's role was not to actively propose ideas but to facilitate the discussion, guard the process and empower the social partners in the CB.

All mediators highlighted conversational and interpersonal skills such as empathy, listening and paraphrasing, as crucial to succeed. Although the main goal is to facilitate the discussion, mediators sometimes provide suggestions to the involved parties.

Opinions differed when asked about the preventative aspect of the mediator role. While some mediators did not see this as part of the larger structure, others saw this as an important aspect and referred to their social network as the most important tool in doing so. Maintenance of their social network was also subject to different opinions. Some mediators emphasized informal and constant contact while others preferred a professional distance from their social partners. Many mediators could not compare their own styles with others' because of the limited information shared between them. 
Parties perceive the mediator generally as neutral and competent and all parties had sufficient trust in both the mediator as well as other members of the CB. Members describe the mediator as an important link in the system and as someone who should have sufficient knowledge about the subject matter whilst understanding both sides of the conciliation board. His role as chair of the joint committee is a major benefit in this sense.

Although generally seen as crucial in reaching a qualitative agreement, some downplayed their role and referred to the procedure itself as crucial. This is in accordance with the mediators' own reflections on the CB. The personality of specific mediators does have a substantial influence during mediation but is primarily summarized into taking a more active or passive stance during negotiations.

Mediators describe the profession itself as exhausting and socially isolated, because of the limited amount of contact between colleagues and demanding workrelated pressure. This pressure will only increase in the future due to attrition of mediators (retirement and other causes) and the current budgetary restraints preventing or limiting the number of new hires. These budgetary restraints affect the entire system's working, from hiring of mediators and translators to providing training and other support.

\subsection{Description of the Facilitation and/or Mediation Process}

\section{Private Sector}

As mentioned earlier, agreements made in the joint committee result in a wellrounded procedure of requesting a mediation. If a party considers a conflict appropriate or severe enough, the request for a CB is filed. Finding an appropriate date for the committee can be tedious because of the schedules of the committee's members. This can lead to a waiting time of several weeks before the committee itself can take place. Timing also depends on urgency of the current conflict and thus a CB forms faster should employee action be imminent.

The CB usually takes place in Brussels at the Belgian Federal Public Service Employment, Labor and Social Dialogue's offices to ensure neutrality. The CB generally only lasts for one day at the most, sometimes until late at night. The precise procedure may differ slightly with respect to the involved mediator, but can be summarized as follows:

1. One of the conflicting parties requests a $\mathrm{CB}$ through the joint committee.

2. The $\mathrm{CB}$ starts with a plenary sitting where the conflicting parties present their case and inform the committee-members. The committee members can ask questions for clarification, but cannot take any positions regarding the subject. Conflicting parties generally have around $10-15$ min to present their case and the mediator's role is largely to facilitate the discussion and clarify the problems presented. CB 
members will generally have already gathered information from their affiliated conflict partners before the CB commences. Given step two, the first step can be seen as 'pre-caucus'.

3. The conflicting parties separate from the committee and each other whilst the committee members initiate negotiations. As a group, they try to supersede the conflict itself-also, representatives from different unions have to overcome potentially differing interests — and try to find an objective solution for both parties.

4. During these negotiations, members of the $\mathrm{CB}$ can consult the conflicting party on its position towards proposed agreements. Alternatively, the mediator can also approach the conflicting parties himself and commute between the two parties. Interviewees describe this part of the process as a 'harmonica movement', where representatives move in and out of discussion by checking with their respective conflict party.

5. After finalizing the negotiations, the $\mathrm{CB}$ ends in a plenary session. At this time, the chair will present the reached agreement or statement of non-agreement. Who presents the agreement or proposition can be a result of political motivations. For instance, the parties might rely upon the moral authority of the mediator as a government official or can prevent a loss of face with the other parties. Conflicting parties must approve the reached agreement. On rare occasions, the mediator will go to the organization to mediate between the conflicting parties directly. This is, however, far from the norm and depends on the nature of the conflict.

Employee/employer organization's representatives mainly propose the solutions, but alternatively the mediator may propose a solution if he/she sees fit. Because the CB generally lasts only one day, negotiations can continue into the night. Failing to reach an agreement results in a non-agreement that can then lead to employee actions. The outcome itself can be one of four categories:

- Parties reach an agreement. Although not legally binding, the involved parties generally respect the agreements.

- Parties do not reach an agreement. Parties will leave the $\mathrm{CB}$ without resolving the conflict. Further action depends on the involved parties and the specific representatives.

- Parties do not reach an agreement but they do make significant towards conciliation. The $\mathrm{CB}$ advises the parties and provides recommendations on how to proceed. Sometimes this entails as a form of 'homework' where parties are stimulated to continue discussions at the organizational level base on committee recommendations. Or, parties can decide to organize a vote among the employees to build stakeholder buy-in.

- Parties, the mediator, of the minister of labor request further mediation at the organization. Prevalence of this type of mediation between the involved parties varies according to sector. This category only happens rarely, no official records are kept. 


\section{Public Sector}

As noted in the previous paragraphs, there is no large presence of structured conciliation when compared to the private sector. There is a less strict regulation or standardization of procedures. The general mediation procedure in the public sector was written down in Committee A (Common committee for all government services), but practical realization of the intervention was left up to the individual mediator. The general procedure, based on our interviews, is as follows:

1. A government agency or union requests mediation. The mediator then assesses the willingness of the other involved party to enter mediation.

2. If there is no danger of immediate escalation, the mediator hears the involved parties individually. The mediator and the parties formulate rules relating to actions in the near future (such as planned strikes) and the subject of the planned intervention.

3. The mediator drafts a document that stipulates the subject of the intervention, agreed rules and requirements. Parties must approve this document before advancing.

4. Plenary meeting led by the mediator is organized with a limited number of participants. If the participant group is too large, some participants remain in a different room for further consultation during the negotiation.

5. Based on this discussion/negotiation, the mediator puts together a report concerning the conclusion or the reached agreement. The mediator has more liberties regarding content and timing of the document in the public sector. It is therefore possible to vary the duration and timing of the intervention and its steps according to specific conflict needs.

The mediator requested the attendance of government/political representatives during these meetings, otherwise negotiations would often falter due to lack of mandate.

\section{Evaluation by stakeholders of the mediators and mediation process}

\section{Mediators/facilitators}

The mediators describe that both the system and the mediator are neutral in the interventions and actions. Their role as civil servant means that they do not have an interest in siding with one of their parties in the conflict, while the location in Brussels ensures it takes place on neutral ground.

The mediators credit the success of the conciliation procedure to the working of the system/procedure itself and the other participants of the CB. These members are active at the sector level and their collaboration transcends the organizational conflict in both time and scope. These partners are therefore required to enter future negotiations such as joint committees resulting in attitudes and expectations that are solution-focused. Mediators see a non-agreement in the CB often as a starting point for further talks rather than the end-point, because of the interdependency of the parties involved. 
The mediators therefore see their main purpose in facilitating the discussion and guarding the process while they perceive the social partners and structure of the system as the key factor for success. Mediators perceive the organization of interventions at the organizational level directly, instead of having a CB at the sector level, to potentially undermine the relevance of sector dialogue and therefore undermine its functioning (including joint committee).

\section{CB members}

The CB is best suited to handle conflicts regarding a more practical nature such as interpretation of previous agreements as opposed to conflicts based on matters of principle. The committee members were often present when they reached previous labor agreements. Hence, members can therefore provide solutions when conflicts revolve around interpretation or implementation of those agreements.

Interviewees indicate that they put less emphasis on exploring issues/interests underlying present conflicts. Nor is rebuilding of trust and relationships a primary focus of the $\mathrm{CB}$. Interviewees describe this as a responsibility of the conflicting parties although the $\mathrm{CB}$ will provide recommendations and advice on how and what to discuss further.

At a $\mathrm{CB}$, the conflict is lifted from the involved parties and their emotional circumstances and evaluated from a "helicopter view". In this sense, interviewees state that CBs not necessarily provide a solution to the conflict, but they do produce new and valuable insights or common ground, which in turn serve as a base for future negotiations. Interviewees describe that the process of coming to Brussels, experiencing the procedure and the fact that a third party takes the conflict seriously reduces emotions and conflict intensity on its own. Members of the CB can see this as a mediation/facilitation amongst the members of the $\mathrm{CB}$ themselves; however, parties at the organizational level can also describe it as a form of arbitration by the parties at organizational level.

Although preferences vary according to sector, interviewees perceived active involvement of the mediator as a positive experience. Members expect the mediator to propose solutions when needed; this requires sufficient authority as well as necessary knowledge about the sector and parties.

Interviewees note an evolution towards a more regulated and legislative society in which mutual understanding and trust seem to be of less importance. This can result in an increased presence of legal assistance at CBs. Presence of lawyers is tolerated or denied depending on sector, but universally seen as limiting the margins when reaching an agreement. Interviewees see this standardization and regulation as a threat to the CB's relevance as it would often come down to interpreting already stipulated guidelines.

\section{Conflicting parties}

In accordance to earlier findings, interviewees see the $\mathrm{CB}$ is as a tool to provide new insights and perspectives or structural solutions to the conflict at hand. Committee members are too far removed from the conflict and its history to fully immerse themselves in the situation. When conflicts occur revolving around larger problems than 
the most recent conflict, current procedure is not an optimal fit. Interviewees perceive the information sharing during the first plenary session of a CB is as insufficient and information is lost in communications between all different levels of involved parties. In these cases, interviewees see direct mediation with conflicting parties as the better option to get to the core of the conflict.

Additionally, interviewees experience the procedure as tiring and long although no mention is made of this having a drastic effect on the reached agreement.

Because of the collective setting, the CB will try to reach an agreement by compromise where all parties are satisfied. Although the goal of compromise is to provide a win-win situation, it is said to often end up in a lose-lose situation. This can be prevented by actively working towards a solution in the time leading up to an $\mathrm{CB}$ and proposing this idea to the committee members who will then further discuss and elaborate on this idea.

Because of the moral authority of both the $\mathrm{CB}$ and the mediator, solutions proposed by the mediator might be agreed to whereas similar solutions at the organizational level would be rejected by the conflicting parties and can be a solution in politically delicate conflicts or negotiations.

\subsection{Effectiveness of the System}

As mentioned earlier, the Belgian Federal Public Service Employment, Labor and Social Dialogue does not structurally document specific numbers regarding CBs as they do not want to create the perception that a non-agreement equals to a failure of the social dialogue.

There is no form of evaluation institutionalized and mediators do not structurally discuss cases among each other. A monthly staff meeting exists. Given the workload, mediators usually use this moment to inform each other regarding practical information such as new laws or the department's official standpoint on current affairs. If cased-based knowledge sharing takes place, mediators do so on an ad hoc basis. Due to their busy schedules and constant meetings and involvement in different sectors, mediators are in fact working within their own silo and have limited contact within their own organization.

With regard to evaluations of personal effectiveness, mediators mostly referred to procedural factors such as facilitating the discussion, general atmosphere during the negotiation, guarding the process and ensuring all parties feel that they are heard sufficiently. All these elements are necessarily in order to reach an effective agreement between the parties.

\section{Evaluation by stakeholders of the effectiveness of the mediation}

Interviewees see CBs as effective and working properly in their current form, taking into account their often-cited use as a stepping-stone for further negotiations. There are however concerns that the current system will no longer suffice in the future. 
Interviewees sometimes describe CBs and the larger procedure concerning social dialogue as conservative institutions that respond slowly to new demands or new types of organizations. Besides concerns towards future effectiveness, CBs are not seen as the optimal fit for acute conflicts due to attendance requirements. In addition, restricting the meeting to one day also limits resolutions in deeper conflicts to a certain extent.

Some interviewees make an additional remark in regards to knowledge about the goals and procedure of the CB. Involved parties note that from their experience education by unions was somewhat lacking and new managers were often not familiar with sector protocols.

\subsection{Conclusions}

One cannot evaluate CBs without taking the larger system of social dialogue into account. Because of its long history and widespread use, it has become an institution known to all parties in the private sector. Its function of providing solutions as well as helping conflicting parties to deepen negotiations has become one of the cornerstones for the Belgian system in the private sector.

Involved parties support the system who generally see it as a crucial step in conflict development with a focus on prevention of strikes.

The public sector does not have a long-standing tradition of mediation. This provides an opportunity for the public sector, as they can analyze the strengths of the system in the private sector and use it to their own advantage.

Because of the additional responsibilities in joint committees, mediators are stretched thin as it is and further budget-cuts will quite realistically undermine the quality of conflict resolution throughout Belgium.

The current procedure has a very strong focus on resolving the acute nature of conflicts while underlying interests can receive less exposure. It can therefore be worthwhile to explore options allowing for a more direct mediation between parties if needed, greater attention to post-conciliation activities or to have a more flexible approach to timing instead of trying to restrict the CB to just one day.

Concerns are also raised about the system's ability to respond to market changes and organization of tomorrow, companies as Deliveroo for example pose difficulties when trying to fit them into the current procedures.

Instituting a formal way of evaluating the procedures, ideally incorporating perspectives of all parties, could allow the Belgian Federal Public Service Employment, Labor and Social Dialogue to improve on their services and adapt to changes and demands more rapidly.

Finally, investing in mediation training (both for conflicting parties and mediators), and structural dialogue among mediators can further improve a consistent and effective process. 
Acknowledgements Dimitri Knockaert, Lieve Verboven, Sonja Broucke, Martin Euwema, Valeria Pulignano.

\section{References}

Devos, C. (2009). Solidariteit in beweging: Perspectieven voor de vakbond van morgen. ASP/VUBPRESS/UPA.

Devos, C., Carl, D., Mus, M., \& Humblet, P. (2011). De toekomst van het sociaal overleg. Academia Press.

European Foundation for the Improvement of Living and Working Conditions. (2006). EIRO thematic feature: Collective dispute resolution in an enlarged European Union. Retrieved from Eurofound: https://www.eurofound.europa.eu/.

FOD WASO. (2017, October 12). Sociale bemiddeling. Retreived from Federale Overheidsdienst Werkgelegenheid, Arbeid en Sociaal Overleg: http://www.werk.belgie.be/defaultTab.aspx?id= 516.

Humblet, P., \& Cox, G. (2011). Collectieve conflicten. Wolters Kluwer Belgium.

Institut der deutschen Wirtschaft. (2017). Industrial relations report. Retrieved from German Economic Institut: https://www.iwkoeln.de/en.html.

Nationale Arbeidsraad. (1968). Wet van 5 December 1968 betreffende de collectieve arbeidsovereenkomsten en de paritaire comités. Retrieved from Nationale Arbeidsraad: http://www. cnt-nar.be/DOC-DIVERS/Wet-Loi-05.12.1968.pdf.

Van Gyes, G., Segers, J., \& Henderickx, E. (2009). In het gelijke onze verschillen ... Het Belgische collectieve systeem van arbeidsverhoudingen gespiegeld aan Nederland. Tijdschrift voor HRM/Nederlandse Vereniging voor Personeelsbeleid.-Deventer, 1, 67-96.

Open Access This chapter is licensed under the terms of the Creative Commons Attribution 4.0 International License (http://creativecommons.org/licenses/by/4.0/), which permits use, sharing, adaptation, distribution and reproduction in any medium or format, as long as you give appropriate credit to the original author(s) and the source, provide a link to the Creative Commons license and indicate if changes were made.

The images or other third party material in this chapter are included in the chapter's Creative Commons license, unless indicated otherwise in a credit line to the material. If material is not included in the chapter's Creative Commons license and your intended use is not permitted by statutory regulation or exceeds the permitted use, you will need to obtain permission directly from the copyright holder.

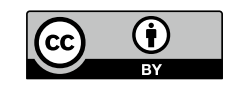

